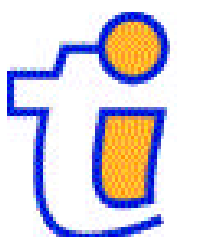

TI 2000-044/1

Tinbergen Institute Discussion Paper

Competitive Bidding in Auctions with Private and Common Values

Jacob K. Goeree

Theo Offerman 
Tinbergen Institute

The Tinbergen Institute is the institute for economic research of the Erasmus Universiteit Rotterdam, Universiteit van Amsterdam and

Vrije Universiteit Amsterdam.

Tinbergen I nstitute Amsterdam

Keizersgracht 482

1017 EG Amsterdam

The Netherlands

Tel.: +31.(0)20.5513500

Fax: $\quad+31 .(0) 20.5513555$

Tinbergen I nstitute Rotterdam

Burg. Oudlaan 50

3062 PA Rotterdam

The Netherlands

Tel.: $\quad+31 .(0) 10.4088900$

Fax: $\quad+31 .(0) 10.4089031$

Most TI discussion papers can be downloaded at

http://www.tinbergen.nl 


\title{
Competitive Bidding in Auctions with Private and Common Values
}

\author{
Jacob K. Goeree and Theo Offerman
}

November 1999

\begin{abstract}
The objects for sale in most auctions display both private and common value characteristics. This salient feature of many real-world auctions has not yet been incorporated into a strategic analysis of equilibrium bidding behavior. This paper reports such an analysis in the context of a stylized model in which bidders receive a private value signal and an independent common value signal. We show that more uncertainty about the common value results in lower efficiency and higher profits for the winning bidder. Information provided by the auctioneer decreases uncertainty, which improves efficiency and increases the seller's revenue. These positive effects of public information disclosure are stronger the more precise the information. Efficiency and revenues are also higher when more bidders enter the auction. Since our model nests both the private and common value case it may lead to an improved specification of empirical models of auctions.
\end{abstract}

JEL Classification: C72, D44.

Keywords: Auctions, inefficiencies, information disclosure, competition.

Goeree: Department of Economics, 114 Rouss Hall, University of Virginia, Charlottesville VA 22901; Offerman: CREED, University of Amsterdam, Roetersstraat 11, 1018 WB Amsterdam, The Netherlands. We acknowledge financial support from the National Science Foundation (SBR-9818683) and the Dutch Organization for Scientific Research (NWO). We should like to thank Maxim Engers, Wake Epps, Charlie Holt, Loren Pitt, Jan Potters, Randolph Sloof, Joep Sonnemans, Michelle Sovinsky, and John Turner for useful discussion. 


\section{Introduction}

Auctions have traditionally been divided into two categories. In private value auctions, bidders know their own value for the commodity with certainty but are unsure about others' valuations. Vickrey (1961) provides an early strategic analysis of private value auctions for the case when values are independent across bidders. The standard textbook example associated with his model is the selling of a painting; buyers' valuations for the painting may differ but are assumed to be independent. In contrast, common value auctions pertain to situations in which the object for sale is worth the same to everyone, but bidders have different private information about its true value. A well known example where the common value setup applies is the auctioning of oil drilling rights, which, to a first approximation, are worth the same to all competing bidders. Common value models were introduced by Wilson $(1969,1977)$ who also provided the first equilibrium analysis of the winner's curse. See Klemperer (1999) for a comprehensive survey of this early literature and more recent advances in auction theory.

Most auctions, however, are not exclusively common value or private value. In his extensive survey of empirical studies on auctions, Laffont (1997) concludes: "In general, economic theory is not able to tell us in which particular model we are. Most empirical studies clearly involve some private value element as well as some common value element ..." For instance, when a painting is auctioned to a private collector, it may be resold in the future and the resale price will be the same for all bidders. This adds a common value component to the auction. And in the oil drilling example, private value differences may arise when a superior technology enables some firms to exploit the rights better than others.

This paper develops a model in which bidders' information consists of both private and common value components. Our stylized two-signal model nests the two paradigms of auction theory in the simplest possible way. The main focus of this paper is on a strategic analysis (à la Vickrey and Wilson): we derive the equilibrium bidding functions for our model and make explicit how they vary with the private and common value signals. Our analysis generates insights about efficiency, winner's profit, and revenues in auctions with private and common value elements, insights that could not have been obtained from a private or common value model alone.

For example, in the absence of reserve prices and entry fees, efficiency is not an issue in (symmetric) private or common value auctions. In the independent private values context, for 
instance, Vickrey (1961) has shown that optimal bids are increasing in bidders' values, and hence, the object is awarded to the bidder that values it the most. And in common value auctions, all bidders value the object the same, so any allocation rule is (trivially) efficient. However, when bidders possess both private and common value information, inefficiencies should be expected. The intuition for this result is straightforward: a bidder with a moderate private value and an overly optimistic estimate of the common value may outbid a rival with a superior private value but more realistic conjectures about the common value.

Maskin (1992) first pointed out that auctions may result in inefficient allocations when signals are multi-dimensional, a result that has been generalized by Jehiel and Moldovanu (1999) by allowing for allocative externalities. Dasgupta and Maskin (1999) also extend Maskin's earlier work and show that a generalized Vickrey auction provides a "second best" mechanism in the sense that it is "constrained efficient." An interesting related paper is that of Pesendorfer and Swinkels (1999). In the context of a two-signal, uniform price auction, they derive conditions under which efficiency is restored when the number of bidders becomes large. None of these papers, however, contains a strategic analysis. Dasgupta and Maskin and Jehiel and Moldovanu prove their results using mechanism design arguments without characterizing the optimal bidding functions. Such a characterization is also lacking in Pesendorfer and Swinkels (1999), who remark that "As a consequence of the two-dimensional type space we have not been able to prove existence of equilibrium. Our results instead hinge on a partial characterization of what equilibria must look like in the limit, if they exist." Existence in their setup is not guaranteed, however, as Jackson's (1999) counterexample shows.

In contrast, we explicitly derive the equilibrium for our model, which makes it possible to determine the extent of inefficiency that can result from the use of auctions. We show that more uncertainty about the common value implies a higher level of expected inefficiency. In the limit when the uncertainty about the common value is so large as to override the private value information, auctions are no more efficient than a random allocation rule. In the other extreme when there is no uncertainty about the common value at all, the auction reduces to an efficient private value auction. Interestingly, the profit of the winning bidder is higher with more uncertainty. The intuition is that, with more uncertainty, bidding has to be more cautious to avoid the winner's curse, which leads to higher profits for the winning bidder. 
The observation that more uncertainty about the object's value results in more inefficiency has implications for the auctioning of (government) licenses to operate in a market. The cost structure of bidding firms constitutes a private value element in such cases, while the uncertain demand for the consumer products introduces a common value aspect. The efficiency losses that can be expected in these situations may be lessened when firms repeatedly participate in similar auctions, since this provides them with the opportunity to learn about consumer demand. For instance, vendor locations at fairs are often auctioned on an annual basis which enables bidders to accumulate information about demand over time. Consequently, the common value of the location can be determined more precisely, thereby reducing possible efficiency losses. In contrast, the infrequent auctioning of landing slots at airports involves more uncertainty about the common value, since bidders face the difficult task of predicting consumer demand for a longer period. The FCC auctions used to allocate the spectrum provide another example where the uncertainty about the common value aspect is likely to be large. First, these auctions are held infrequently. Second, estimating demand is even more complicated when the frequencies are used in emerging markets like the market for mobile phones. As a result, efficiency losses may be more pronounced.

Another benefit of our strategic analysis is that it is possible to evaluate policies to enhance efficiency and revenues. One such measure is the disclosure of the auctioneer's information about the common value. When this information is made public, uncertainty about the common value decreases, which raises efficiency. On average, the auctioneer's revenue is also higher when information is revealed, which makes it likely that such disclosure will indeed occur. The intuition is that with less uncertainty, bidding will be more aggressive. The positive effects of publicly announcing the auctioneer's information are stronger the more precise the information. Another factor improving efficiency is an increase in competition: expected efficiency and expected revenue increase with each extra bidder. In the limit when the number of bidders goes to infinity, an efficient allocation again materializes. Interestingly, the effect of more competition on efficiency and revenues is stronger than the effect of information provided by the auctioneer. When the seller has the choice between finding more interested bidders or 
providing information about the value of the commodity, she should choose the former. ${ }^{1}$

This paper is organized as follows. Section 2 introduces the model. In section 3 we derive the summary statistic and discuss when a reduction to a one-dimensional signal is possible. Section 4 characterizes the equilibrium for all standard auctions (first price, second price, and English) and provides general formulas for the auctioneer's revenue, the winner's profit, and total surplus. In section 5 we show that more uncertainty about the common value results in a higher level of inefficiency. Section 6 discusses the effect of an auctioneer's report on revenue and efficiency, and section 7 considers the effects of increased competition. The results are illustrated with an example in section 8 , and section 9 concludes.

\section{The Model}

Consider an auction in which $n$ bidders compete for a single object such as a government contract, drilling rights for an offshore tract, the right to use a certain radio frequency, etc. Suppose bidder $i=1, \ldots, n$, has an unbiased estimate, or common value signal, $v_{\mathrm{i}}$, of the object's true value, $V$, which is the same for all bidders. Two ways to model the common value have been proposed. In the "traditional" formulation (Rothkopf, 1969; Wilson, 1969, 1977) the common value has some known prior distribution and bidders' signals are draws conditional on the particular realization of $V$. This realization, unknown at the time of bidding, is revealed when the object is obtained. ${ }^{2}$ Alternatively, the common value can be modeled as the average of bidders' signals: ${ }^{3}$

1 This result is reminiscent of Bulow and Klemperer's (1996) finding that an optimally structured bargaining process following an auction with $n$ bidders generates less revenue than an auction with $n+l$ bidders.

2 The traditional formulation can be illustrated with the auctioning of oil drilling rights. A (common) prior is formed as bidders repeatedly compete for different tracts. For each new tract to be auctioned, bidders receive an estimate of the true amount of oil.

3 Previous papers that have used the average formulation include: Bikhchandani and Riley (1991), Albers and Harstad (1991), Krishna and Morgan (1997), Klemperer (1998), Bulow and Klemperer (1998), and Bulow, Huang, and Klemperer (1999). One possible motivation for this formulation is the auctioning of the rights to operate in emerging markets. In such cases, no prior information exists about the distribution of the common value and residual uncertainty about the object's true value is likely to remain after the auction is closed. The best approximation for the value of the commodity is then its market resale price. For instance, consider a bidder who enters a spectrum auction with the intent to resell the rights to use the frequency. Prospective buyers will infer others' value signals from their bids and use this information to reevaluate the license's value. Assuming that the 'quality' or precision of signals is uniform across bidders, the best estimate of the resale price of the license is the average of all signals. 


$$
V=\frac{1}{n} \sum_{i=1}^{n} v_{i}
$$

It is important to point out that the two formulations have the same qualitative features. First, the commodity for sale is worth the same to all bidders. Second, in both formulations bidders should realize that winning means that their signal is likely to be too optimistic. In order not to fall prey to a "winner's curse," bidders should shade their bids accordingly. By the law of large numbers the difference between the two formulations disappears completely with an increasing number of bidders. Throughout the paper we shall use the average formulation for the common value for which it is possible to derive the equilibrium bidding functions.

Few people would dispute that most auctions have both private and common value features. For instance, when licenses to operate in a market are auctioned, a common value aspect results from the uncertain demand for the product to be provided, while the different cost structures of the bidding firms adds a private value part. This example motivates the information structure of our model: ${ }^{4}$

Assumption 1. There are $n \geq 2$ risk neutral bidders. Bidder $i=1, \ldots, n$ receives a private cost signal, $c_{i}$, and an independent common value signal, $v_{i}$. Cost and value signals are assumed to be independently and identically distributed across bidders. ${ }^{5}$

The density of cost signals is denoted by $f_{\mathrm{c}}(c)$ with support $\left[c_{\mathrm{L}}, c_{\mathrm{H}}\right]$ where $c_{\mathrm{L}} \geq 0$. Similarly, $f_{\mathrm{v}}(v)$ is the density of value signals, with support $\left[v_{\mathrm{L}}, v_{\mathrm{H}}\right]$. We consider the case where $v_{\mathrm{L}} \geq c_{\mathrm{H}}$, so that bidders will always wish to participate. The assumption of risk neutrality implies that when bidder $i$ receives the object and pays an amount $b$, her net utility is $V-c_{\mathrm{i}}-b$.

\footnotetext{
${ }^{4}$ Obviously, alternative motivations are possible. For instance, the common value signal could pertain to the resale price of a painting, while the private value signal could represent a bidder's own taste for the painting. (We will return to this example in section 8.) Alternatively, in "take-over" battles, the estimated "market value" of the firm could be represented by the common value signal while the private value indicates the expected "value added" of the bidder.

5 The i.i.d. assumption may seem restrictive but is in no way crucial for the analysis of this paper. In the conclusion we discuss the case when values and/or costs are affiliated and argue that, with the exception of revenue equivalence, our results generalize.
} 


\section{From Two to One Dimensions: A Problem?}

Before we give a formal derivation of the equilibrium strategies, it is useful to provide some intuition. When bidders receive multiple signals they must somehow combine the different pieces of information into a summary statistic since their bid is just a single number. Milgrom and Weber $(1982$, p. 1097) point out that "... the derivation of a summary statistic from several pieces of information is in general a difficult task ..." For our model, however, the summary statistic follows from the following observation. A bidder's expected payoff in an auction is: $\pi^{\mathrm{e}}=($ expected gain - expected payment $) \times$ probability of winning. The expected payment and the probability of winning are independent of a bidder's private and common value signals (but will depend on her bid and others' bidding strategies). Moreover, for the average formulation of the common value, bidder $i$ 's expected gain equals her "surplus," $s_{\mathrm{i}}=v_{\mathrm{i}} / n-c_{\mathrm{i}}$, plus terms that are independent of her signals. ${ }^{6}$ The first-order conditions for profit maximization therefore determine optimal bids in terms of a her surplus, $s_{\mathrm{i}}$.

From a bidder's point of view, the information contained in the cost and value signals is thus adequately summarized by a one-dimensional surplus signal. Before applying the standard apparatus developed for univariate signals, however, we have to deal with the following caveat: in general, a higher surplus does not imply a higher value signal, and hence, optimal bids may not be increasing in surplus. This problem is illustrated by the following two-bidder example.

Example 1. Let costs be uniformly distributed on the intervals $[0, .5]$ and $[100,100.5]$, and let values be uniformly distributed on [201, 202] and [399, 400]. With two bidders, surplus is given by $s=v / 2-c$, which is (non-uniformly) distributed on [0,1], [99, 100], [100, 101] and [199, 200]. Note that $99<s<100$ implies $399<v<400$, while $100<s<101$ implies $201<v<202$, so $\mathrm{E}(v \mid s)$ is not monotonically increasing in $s$. Now, suppose, in contradiction, that optimal bids are increasing in surplus and bidder 1, say, has the higher surplus. The expected value of the object to bidder 1 is given by $1 / 2 v_{1}+1 / 2 \mathrm{E}\left(v \mid s \leq s_{1}\right)-c_{1}=s_{1}+1 / 2 \mathrm{E}\left(v \mid s \leq s_{1}\right)$. It is straightforward to show that $\mathrm{E}(v \mid s \leq 100)=300.5$ and $\mathrm{E}(v \mid s \leq 101)=266.5$, so the expected value is $250^{1 / 4}$ for $s_{1}=100$ and $2341 / 4$

6 The use of the word surplus for $s_{\mathrm{i}}=v_{\mathrm{i}} / n-c_{\mathrm{i}}$ is somewhat misleading since a bidder's true surplus from the auction (in case she wins) is $V-c_{\mathrm{i}}$. A bidder's "type" would be a more correct, though less informative, name for $s_{\mathrm{i}}$. 
for $s_{1}=101$. Hence, optimal bids cannot be increasing in surplus.

The underlying problem is that there is no natural way to order signals in two-dimensions. As a result, a one-dimensional statistic may not adequately rank bidders from low to high valuations. This problem would not occur if a higher surplus signaled "good news" about the value, i.e. when a higher surplus implies, on average, a higher value. Example 1 shows that this property cannot be expected when the densities of cost and value signals are not unimodal. To avoid problems of non-monotonicity and non-existence we shall restrict ourselves to the following class of unimodal densities.

Assumption 2. The densities $f_{v}(v)$ and $f_{c}(c)$ are logconcave.

Logconcavity means that the (natural) $\log$ of the density is concave. This mild restriction is met by many commonly used densities such as the uniform, normal, chi-square, exponential densities, etc. ${ }^{7}$ The next lemma shows that the assumption of logconcavity ensures that surplus and values are positively correlated (see the Appendix for a proof).

Lemma 1. Under Assumption 2, the conditional expectations $E(v \mid s=x)$ and $E(v \mid s \leq x)$ are nondecreasing in $x$. Furthermore, $E(c \mid s=x)$ and $E(c \mid s \leq x)$ are non-increasing in $x$.

We are now ready to derive the equilibrium bidding functions for our model, which is the topic of the next section. We shall follow Milgrom and Weber (1982) who characterize the equilibrium for standard auctions when bids are based on a single summary statistic. Since we already determined how this summary statistic is constructed from the private and common value signals, the derivation of the equilibrium bidding functions is fairly straightforward. Our main interest, however, concerns the study of interesting economic phenomena such as the effects of uncertainty, public release of information, and competition on efficiency and revenues.

7 See, for instance, Caplin and Nalebuff (1991) for a more extensive list and for applications of the logconcavity assumption in models of oligopolistic competition. 


\section{Equilibrium Strategies, Revenues, Winner's Profit, and Total Surplus}

We start with the first-price auction, then we consider the second-price auction and finally the English auction. ${ }^{8}$ Due to symmetry we can, without loss of generality, focus on bidder 1 whose surplus is given by $s_{1}=v_{1} / n-c_{1}$. Lower case letters are used to denote the highest surplus of the $(n-1)$ other bidders, e.g. $y_{1}=\max _{\mathrm{j}=2, \ldots, \mathrm{n}}\left(v_{\mathrm{j}} / n-c_{\mathrm{j}}\right)$, and capital letters indicate order statistics when they pertain to all $n$ bidders, e.g. $Y_{1}$ is the maximum of $n$ surplus draws. To keep the notation simple we only use one expectation symbol, e.g. the expected cost of the winner $\mathrm{E}\left(c_{\text {winner }}\right)=\mathrm{E}_{\mathrm{Y} 1}\left(\mathrm{E}\left(c \mid s=Y_{1}\right)\right)$ is simply written as $\mathrm{E}\left(c \mid s=Y_{1}\right)$. The proofs of the propositions in this section can be found in the Appendix.

Proposition 1. The n-tuple of strategies $(B(\cdot), \ldots, B(\cdot))$, where

$$
B(x)=E\left(V-c_{1} \mid s_{1}=x, Y_{1}=x\right)-E\left(Y_{1}-y_{1} \mid s_{1}=x, Y_{1}=x\right),
$$

is an equilibrium of the first-price auction.

Note that the optimal bids are functions of surplus, the summary statistic in our model. The intuition behind (2) is as follows: the first term on the right side represents what the commodity is worth (on average) to a bidder assuming that her surplus, $x$, is the highest and the second term shows how much she "shades" her bid.

Next we turn to a second-price auction in which the highest bidder wins at the second highest price. The optimal bid function for this case is the same as for the first-price auction except that a bidder now assumes that she has the highest surplus and one other bidder has that same surplus. The shade term on the right side of (2) therefore disappears.

Proposition 2. The n-tuple of strategies $(B(\cdot), \ldots, B(\cdot))$, where

$$
B(x)=E\left(V-c_{1} \mid s_{1}=x, y_{1}=x\right) \text {, }
$$

is an equilibrium of the second-price auction.

\footnotetext{
8 We will not discuss the Dutch auction separately, since it is strategically equivalent to the first-price auction.
} 
Note the resemblance between (3) and Vickrey's dominant strategy solution for the private value second-price auction, i.e. bidding one's value. When the expected value of the commodity depends on others' information, a dominant strategy no longer exists. Instead, a bidder's optimal strategy is to bid the expected value assuming she has the highest surplus and this surplus is equal to the second highest surplus. To see this, note that if she bids less than (3) while others bid according to (3), she could lose from bidders with a slightly lower surplus than hers and forego some profit. Alternatively, if she bids higher than (3), she could win from bidders with a slightly higher surplus than hers and pay too much, resulting in a negative profit.

Since our model contains the standard private value auction and common value auction as special cases, it is interesting to see how bidding behavior in these familiar settings compares with the results of Propositions 1 and 2. For instance, in the independent private values model, increased competition leads to more aggressive bidding because an increase in the number of bidders reduces the chance of winning. The opposite effect of the number of bidders on optimal bids is predicted for the common value model, at least for some examples. The intuition is that with more bidders, winning is more informative, i.e. an even stronger indication that the winner's signal was "too optimistic." Sometimes these contradicting comparative statics results are used in empirical work to determine which model applies: private or common value (Paarsch, 1992). In our model, in which bidders possess both private value and common value information, there is no clearcut effect of increasing the number of bidders: optimal bids may increase, decrease, or may be non-monotonic in the number of bidders. The procedure to classify the auction on the basis of this numbers effect may therefore be less useful.

To get some insight into this result, consider a bidder with a low value and low cost signal. With only one competitor, winning signals bad information about the other's value and, hence, about the value of the object for sale. In order not to fall prey to a winner's curse, the optimal bid has to take this adverse selection effect into account. In contrast, with an infinite number of bidders, a bidder's value signal becomes irrelevant and optimal bids are based on costs only. In this case, the expected value of the object is simply its unconditional expected value. So, with a low cost and value signal, the optimal bid is higher with an infinite number of bidders than with two bidders. However, an analogous argument shows that bidders with high cost and high value signals bid less with more rivals. 
Figure 1 illustrates the dependence of optimal bids on the number of bidders in a secondprice auction when values are uniformly distributed on [2, 3] and costs are uniformly distributed on $[0,1]$. The optimal bid decreases with $n$ when $(v, c)=(3, .1)$, is non-monotonic when $(v, c)$ $=(2.4, .05)$, and increases with $n$ when $(v, c)=(2.3, .01)$. Notice that the ranking of bidders may change with the number of bidders, e.g. the bidder with $(v, c)=(3, .1)$ outbids the other two when $n \leq 8$ but has the lowest bid when $n \geq 12$. Hence, the introduction of new bidders may change the winner of the auction and make it more efficient (see section 7), even when these bidders themselves have no chance of winning. The intuition behind this result is that when more bidders enter the auction, the common value signal becomes less important, which exemplifies the cost differences between firms and makes an efficient outcome more likely.
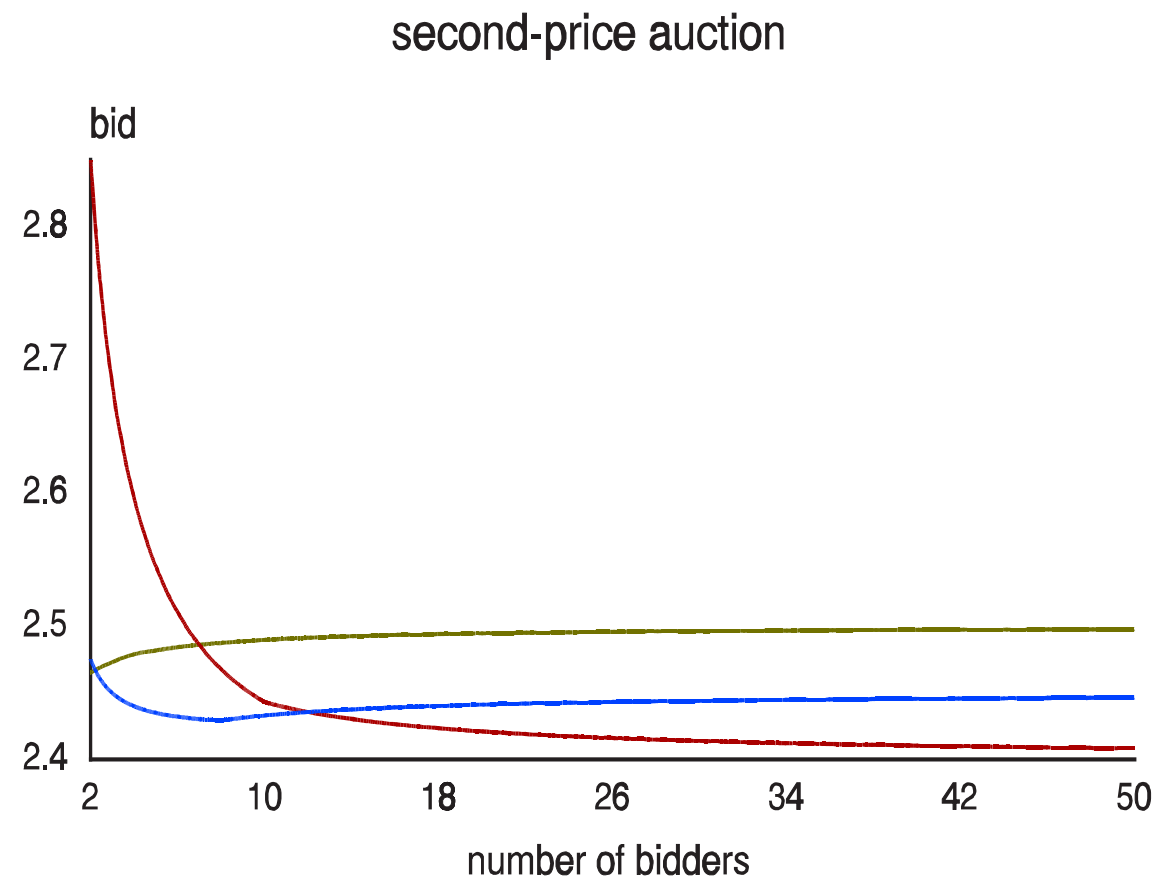

Figure 1. Optimal bids in a second-price auction.

Our derivation of the optimal bidding functions for the English auction follows Milgrom and Weber (1982). In the variant we consider, the auctioneer continuously raises the price and bidders publicly reveal when they withdraw from the auction. Bidders who have dropped out 
are not allowed to reenter. With only two bidders, a bidder's strategy is described by a single number that indicates how high the bidder is willing to go before conceding: the English auction with two bidders is equivalent to a second-price auction. However, with more than two bidders the prices at which some bidders drop out convey information to those who remain active. Suppose $k$ bidders have dropped out at bid levels $b_{1} \leq \ldots \leq b_{\mathrm{k}}$. Bidder 1's strategy can be described by functions $B_{\mathrm{k}}\left(s_{1} ; b_{1}, \ldots, b_{\mathrm{k}}\right)$ which specify how high bidder 1 is willing to bid given that $k$ bidders dropped out at levels $b_{1}, \ldots, b_{\mathrm{k}}$ (and given her surplus $s_{1}$ ). The equilibrium strategy $B(\cdot)=\left(B_{0}(\cdot), \ldots, B_{\mathrm{n}-2}(\cdot)\right)$ is then defined recursively.

Proposition 3. The n-tuple of strategies $(B(\cdot), \ldots, B(\cdot))$, with $B(\cdot)$ defined in (4), constitutes an equilibrium of the English auction.

$$
\begin{aligned}
B_{0}(x) & =E\left(v_{1}-c_{1} \mid s_{1}=x\right), \\
B_{k}\left(x ; b_{1}, . ., b_{k}\right) & =\frac{n-k}{n} E\left(v_{1} \mid s_{1}=x\right)-E\left(c_{1} \mid s_{1}=x\right)+\frac{1}{n} \sum_{j=0}^{k-1} E\left(v_{1} \mid B_{j}\left(s_{1} ; b_{1}, \ldots, b_{j}\right)=b_{j+1}\right) .
\end{aligned}
$$

The intuition for (4) is straightforward: given her surplus and the information conveyed in others' drop-out levels, the highest a bidder is willing to go is given by the expected value of the commodity assuming that all other active bidders have the same surplus. For instance, consider the bid function $B_{0}\left(s_{1}\right)$ which pertains to the case when no bidder has dropped out yet. If all other bidders were to drop out at level $B_{0}\left(s_{0}\right)$, then bidder 1's expected payoff is: $s_{1}+(n-1) / n$ $\mathrm{E}\left(v \mid s=s_{0}\right)-B_{0}\left(s_{0}\right)=s_{1}+(n-1) / n \mathrm{E}\left(v \mid s=s_{0}\right)-\mathrm{E}\left(v-c \mid s=s_{0}\right)=s_{1}-s_{0}$. Using the bidding strategy $B_{0}$, bidder 1 remains active until she is indifferent between winning or quitting. Similar interpretations can be given for the $B_{\mathrm{k}}$ with $k \geq 1$; the only difference is that these functions take into account the information conveyed in others' drop-out levels.

We end this section with a "revenue and efficiency equivalence" result. Our model predicts that the seller's profit is the same for all standard auctions thereby providing a more general setting for which Vickrey's celebrated revenue equivalence result holds. Interestingly, 
our model also predicts that efficiency is the same for all standard auctions. ${ }^{9}$ One might have expected that an English auction would be more efficient than a sealed-bid auction. In an English auction, part of the uncertainty about the common value is resolved as the remaining bidders observe the price levels at which low-surplus bidders drop out. These price levels reveal their surpluses and thus provide information about their value signals. In the final stage of the English auction with only two active bidders left, all but one of the surpluses have been revealed, allowing for more precise beliefs about the common value. However, for the remaining uncertain part it is still the case that the bidder with the higher surplus makes the higher bid. Thus, the first-price, second-price, and English auctions are efficiency equivalent because in all three auctions the bidder with the highest surplus wins.

Proposition 4. In all three auctions, the total expected surplus generated is $W=E(V)-E\left(c_{\text {winner }}\right)$, the winner's expected profit is $\pi_{\text {winner }}=E\left(Y_{1}\right)-E\left(Y_{2}\right)$, and the auctioneer's expected revenue is $R=W-\left(E\left(Y_{1}\right)-E\left(Y_{2}\right)\right)$.

In words, the expected total surplus generated by the auction is equal to the expected value of the common value minus the winner's expected cost and the winner's expected profit is the expected difference between the highest and second-highest surplus draw. The expected revenue for the auctioneer is simply the difference between expected total surplus and the winner's profit.

In the rest of the paper, we focus on policies aimed at increasing the efficiency and revenue of auctions. In sections 6 and 7 we consider the effects of public information disclosure and increased competition. First, we determine how the degree of uncertainty about the common value affects efficiency.

9 We do not want to stress these equivalence results since they are sensitive to the specific assumptions underlying our model. For instance, it is well known that affiliation and risk aversion destroy revenue equivalence (see Milgrom and Weber, 1982, for revenue comparisons with affiliated signals, and, e.g. Holt, 1980, for the implications of risk aversion for revenues). Efficiency equivalence will most likely not hold for the "traditional" formulation of the common value. (We conjecture that in this case the English auction will be more efficient. This is hard to verify because, so far, it has been impossible to derive the optimal bidding functions for the traditional formulation when bidders receive more than one signal.) In contrast, our results pertaining to the effects of uncertainty, the release of information, and increased competition on efficiency and revenues are all robust. 


\section{The Effects of Uncertainty}

In the previous section we have shown that in all three auctions the bidder with the highest surplus wins. Since this bidder is not necessarily the one with the lowest cost, this creates the possibility of inefficiencies. In this section we determine the magnitude of the possible loss in efficiency and demonstrate that more uncertainty about the common value leads to a greater loss. Furthermore, we show that more uncertainty results in higher profits for the winning bidder.

A natural efficiency measure is the total expected surplus of the auction $W=\mathrm{E}(V)$ $\mathrm{E}\left(c \mid s=Y_{1}\right)$, the pie to be divided by the winning bidder and the auctioneer. A convenient way to parameterize the uncertainty about the common value is to define the surplus variable $s(\alpha)=$ $\alpha v / n-c$ which results by scaling the value signal by $\alpha>0$. Since the analysis presented below only involves surplus differences, additive constants cancel out. The effect of scaling the values by $\alpha$ is therefore the same as a "mean-preserving" transformation of the values. ${ }^{10}$

First, we determine the probability that the low-cost bidder wins the auction as a function of $\alpha$. Intuitively, when surplus contains no information about costs this probability is $1 / n$ while it should be 1 when surplus and costs are perfectly correlated.

Proposition 5. The probability $P(\alpha)$ that the low-cost bidder wins the auction is decreasing in $\alpha$ with $P(0)=1$ and $\lim _{\alpha \rightarrow \infty} P(\alpha)=1 / n$.

Proof. $P(\alpha)$ is given by $\operatorname{Prob}\left[s_{1}(\alpha)=\max _{\mathrm{j}=1, \ldots \mathrm{n}} s_{\mathrm{j}}(\alpha) \mid c_{1}=\min _{\mathrm{j}=1, \ldots \mathrm{n}} c_{\mathrm{j}}\right]$, or

$$
\begin{aligned}
P(\alpha) & =\operatorname{Prob}\left[c_{1}-c_{2}<\alpha\left(v_{1}-v_{2}\right) / n, \ldots, c_{1}-c_{n}<\alpha\left(v_{1}-v_{n}\right) / n \mid c_{1}-c_{2}<0, \ldots, c_{1}-c_{n}<0\right] \\
& =\operatorname{Prob}\left[v_{1}-v_{2}>n\left(c_{1}-c_{2}\right) / \alpha, \ldots, v_{1}-v_{n}>n\left(c_{1}-c_{n}\right) / \alpha \mid c_{1}-c_{2}<0, \ldots, c_{1}-c_{n}<0\right] .
\end{aligned}
$$

The top expression makes it clear that $P(0)=1$ and the bottom expression shows that $P(\alpha)$ is decreasing in $\alpha$ with $\lim _{\alpha \rightarrow \infty} P(\alpha)=1 / n$. Q.E.D.

10 The correct mean-preserving transformation takes the form $v \rightarrow \alpha v+(1-\alpha) \mathrm{E}(v)$. 
Depending on the relative variance of the value and cost signals, the allocation that results from the auction thus ranges from "fully efficient" to "no more efficient than a random allocation." The probability of winning, however, is not necessarily a good measure of inefficiency: even when the lowest-cost bidder does not receive the commodity, the expected cost of the winner could still be very low so that the loss in efficiency is small. The next proposition shows that the winner's expected cost rises with the uncertainty about the common value.

Proposition 6. The expected cost of the winner, $E\left(c_{\text {winner }}\right)=E\left(c \mid s(\alpha)=Y_{I}(\alpha)\right)$, is increasing in $\alpha$.

Proof. Let $\alpha_{1}>\alpha_{2}>0$. Suppose, without loss of generality, that $s_{1}\left(\alpha_{1}\right)=\max _{\mathrm{j}=1, \ldots \mathrm{n}} s_{\mathrm{j}}\left(\alpha_{1}\right)$ and $s_{\mathrm{k}}\left(\alpha_{2}\right)=\max _{\mathrm{j}=1, \ldots \mathrm{n}} s_{\mathrm{j}}\left(\alpha_{2}\right)$. There are two cases to be considered. If $k=1$, the costs are the same for both $\alpha$ 's. If $k \neq 1$, we have: $\alpha_{1} v_{1} / n-c_{1}>\alpha_{1} v_{\mathrm{k}} / n-c_{\mathrm{k}}$ and $\alpha_{2} v_{\mathrm{k}} / n-c_{\mathrm{k}}>\alpha_{2} v_{1} / n-c_{1}$ (ties occur with probability zero). Dividing the first inequality by $\alpha_{1}$ and the second by $\alpha_{2}$ and adding the result yields: $c_{1} / \alpha_{1}+c_{\mathrm{k}} / \alpha_{2}<c_{1} / \alpha_{2}+c_{\mathrm{k}} / \alpha_{1}$, or, equivalently, $c_{\mathrm{k}}\left(1 / \alpha_{2}-1 / \alpha_{1}\right)<c_{1}\left(1 / \alpha_{2}-1 / \alpha_{1}\right)$. Hence $c_{1}>c_{\mathrm{k}}$ when $k \neq 1$. In other words, for some realizations of the value and cost signals, the winner's cost is less for $\alpha=\alpha_{2}$ than for $\alpha=\alpha_{1}$, while it is the same for other realizations. A fortiori, the expected winner's cost (i.e. the winner's cost averaged over all possible realizations of the value and cost signals) is less for $\alpha=\alpha_{2}$. Q.E.D.

Finally, we show that the winner's profit is non-decreasing in the uncertainty about the common value. ${ }^{11}$ The basic intuition is that with less uncertainty the winner's curse problem is softened, which leads to more aggressive bidding and hence to lower profits (the proof can be found in the Appendix).

Proposition 7. The winner's expected profit, $\pi_{\text {winner }}=E\left(Y_{I}(\alpha)\right)-E\left(Y_{2}(\alpha)\right)$, is non-decreasing in $\alpha$.

11 It is important to point out that this result is caused by an increase in the variance of the value signals, not by an increase in the level. Proposition 7 also holds for the mean-preserving transformation $v \rightarrow \alpha v+(1-\alpha) \mathrm{E}(v)$, since adding a constant to all values does not affect profits. Given that total expected surplus decreases under such a mean-preserving transformation of the values (Proposition 6), and the winner's profit is at worst the same, the auctioneer's revenue has to fall with more uncertainty. 
One nice interpretation of our model is that it provides a continuous parameterization from a private values model at one extreme $(\alpha=0)$ to a pure common value model at the other extreme $(\alpha=\infty)$. Recall from the previous section that with $n$ bidders, surpluses are defined as $s=v / n-c$, so that an increase in the number of players has the same effect as reducing $\alpha$. In other words, the auction becomes more and more like a private value auction when competition increases. We will return to this point in section 7. Propositions 5 and 6 show that for the realistic case of $\alpha>0$, full efficiency can no longer be expected. In fact, it is straightforward to verify that the drop in expected total surplus, or equivalently, the increase in the winner's expected cost is

$\mathrm{E}\left(c_{1}\right)-\mathrm{E}\left(c_{1} \mid c_{1}=\min _{\mathrm{j}=1, \ldots, \mathrm{n}} c_{\mathrm{j}}\right)$ when $\alpha$ increases from 0 to $\infty$. Especially when there are relatively more high-cost bidders (i.e. with a skewed cost distribution) the efficiency loss can be substantial. In the next two sections we discuss factors that have a positive effect on efficiency and revenue.

\section{The Effects of Information Disclosure}

In this section we investigate the effects of public information release on bidding behavior, revenues, and efficiency. Positive effects of the disclosure of this information for both revenue and efficiency can be expected since it reduces uncertainty about the common value, which diminishes the winner's curse, and hence leads to more aggressive bidding. Consequently, the expected profit of the winning bidder stays at best the same. Furthermore, a reduction in the uncertainty about the common value results in a higher expected total surplus and since the winner's profit does not increase, the auctioneer's expected revenue goes up. We show that these positive effects are stronger when the auctioneer's information becomes more precise.

In particular, we consider the case in which the auctioneer publicly announces her own private signal $v_{0}$ about the common value $V$. Under the assumption that the precision of this signal is the same as those of the bidders, the common value changes as follows:

$$
V^{\prime}=\frac{1}{n+1} \sum_{i=0}^{n} v_{i} .
$$

The effect of this extra piece of information on bidders' strategies is most easily determined by defining a new surplus variable $s^{\prime}=v /(n+1)-c$. With this new definition the results of section 
4 can be applied without difficulty. ${ }^{12}$ In other words, the expressions for profits, total surplus, and revenues are the same as before, with the surplus signals and the order statistics appropriately redefined. The effects of this redefinition are easily established using Propositions 6 and 7.

Proposition 8. Public disclosure of the auctioneer's information increases total expected surplus, increases expected revenue, and does not raise the winner's expected profit.

Proof. Let $\alpha_{1}=1 / n$ and $\alpha_{2}=1 /(n+1)$. The difference between total expected surplus with and without the auctioneer's signal is given by: $\left[\mathrm{E}(V)-\mathrm{E}\left(c \mid s\left(\alpha_{2}\right)=Y_{1}\left(\alpha_{2}\right)\right)\right]-\left[\mathrm{E}(V)-\mathrm{E}\left(c \mid s\left(\alpha_{1}\right)=Y_{1}\left(\alpha_{1}\right)\right)\right]$, and the surplus result thus follows easily from Proposition 6. Since total expected surplus increases and the winner's profit does not increase by Proposition 7, the auctioneer's expected revenue increases. Q.E.D.

The intuition behind this proposition is that the information given by the auctioneer reduces the uncertainty about the common value. The reduced uncertainty makes the private value component (i.e. the cost signal) more important, which raises the chance that a low-cost bidder wins. At the same time, the reduced uncertainty will lead to more aggressive bidding and thus to higher revenues for the auctioneer. ${ }^{13}$

So far, we have only considered the case in which the auctioneer's signal, $v_{0}$, is of the same quality or precision as the signals of any of the bidders. In many situations, however, the

12 For example, in the first-price auction the optimal bidding function reads: $B(x)=v_{0} /(n+1)+n /(n+1) \mathrm{E}\left(V \mid Y_{1}^{\prime}=x\right)$ $\mathrm{E}\left(c \mid s^{\prime}=x\right)-\mathrm{E}\left(Y_{1}^{\prime}-y_{1}^{\prime} \mid Y_{1}^{\prime}=x\right)$, and similar changes occur for the second-price and English auction. The total surplus conditional on the signal $v_{0}$ equals the expected value of the commodity to the winner. As before, this is given by the first two terms of $B(x)$ evaluated at $x=Y_{1}^{\prime}$ :

$$
W\left(v_{0}\right)=\frac{n}{n+1} E(V)+\frac{1}{n+1} v_{0}-E\left(c \mid s^{\prime}=Y_{1}^{\prime}\right)
$$

Since $\mathrm{E}\left(v_{0}\right)=\mathrm{E}(V)$, the unconditional total expected surplus is $W=\mathrm{E}(V)-\mathrm{E}\left(c \mid s^{\prime}=Y_{1}^{\prime}\right)$. Similarly, the winner's profit becomes $\pi_{\text {winner }}=\mathrm{E}\left(Y_{1}^{\prime}\right)-\mathrm{E}\left(Y_{2}^{\prime}\right)$ and the auctioneer's revenue is $R=W-\pi_{\text {winner }}$.

13 One may wonder whether a truthful report is in the auctioneer's best interest. Milgrom and Weber (1982) present theoretical arguments why no reporting policy leads to a higher expected revenue than the policy of always reporting honestly. Ashenfelter (1989) provides empirical evidence that auctioneers' price estimates of impressionist paintings are "very highly correlated with the actual prices fetched" and that the estimates are "very close to unbiased." 
auctioneer may be better informed about the commodity's true value. A natural way to model this is to weigh the auctioneer's signal by a factor $\lambda>1$. The expression for the common value then becomes $V=\left(\lambda v_{0}+\sum_{\mathrm{i}=1}^{\mathrm{n}} v_{\mathrm{i}}\right) /(n+\lambda){ }^{14}$

Proposition 9. An increase in the quality of the auctioneer's information leads to higher expected total surplus, higher expected revenue, and does not raise the winner's expected profit.

Proof. Define $\alpha_{1}=1 /\left(n+\lambda_{1}\right)$ and $\alpha_{2}=1 /\left(n+\lambda_{2}\right)$ with $\lambda_{2}>\lambda_{1}$. The proof is analogous to that of Proposition 8. Q.E.D.

\section{The Effects of More Competition}

In this section we investigate what happens when more bidders enter the auction. The effect of increased competition can be treated along the same lines as the release of public information in the previous section. With $n+1$ bidders, the common value is given by (1) with $1 / n$ replaced by $1 /(n+1)$ and with one signal added. Defining the surplus variable $s^{\prime}=v /(n+1)-c$, the results of section 4 translate as follows: total expected surplus is $W=\mathrm{E}(V)-\mathrm{E}\left(c \mid s^{\prime}=Y_{1}^{\prime}\right)$, the winner's profit is $\pi_{\text {winner }}=\mathrm{E}\left(Y_{1}^{\prime}\right)-\mathrm{E}\left(Y_{2}^{\prime}\right)$, and the auctioneer's revenue is $R=W-\pi_{\text {winner }}$, where the order statistics are now based on $n+1$ draws. The effect of one more bidder on total surplus is therefore twofold: the surplus variable is redefined (which has a positive effect on efficiency, see section 6) and the number of draws is increased. To isolate the latter effect, we shall consider the case of $n+1$ bidders whose surpluses are the same as when there are $n$ bidders. Let $s^{\prime}(\alpha)=\alpha v /(n+1)-c$ in which the values are scaled by a factor $\alpha$, then $s^{\prime}\left(\alpha_{0}\right)=s$ for $\alpha_{0}=(n+1) / n$. The proof of the next lemma can be found in the Appendix.

Lemma 2. $E_{n+1}\left(c \mid s^{\prime}\left(\alpha_{0}\right)=Y_{l}^{\prime}\left(\alpha_{0}\right)\right) \leq E_{n}\left(c \mid s=Y_{l}\right)$.

14 This formulation can be motivated as follows: consider the case in which the variance of the bidders' signals is $\sigma_{b}^{2}$ (the same for all bidders) and the variance of the auctioneer's signal is $\sigma_{\mathrm{s}}^{2}$. The "best" (i.e. unbiased and smallest variance) estimator of the commodity's value is then given by $V=\left(\lambda v_{0}+\sum_{\mathrm{i}=1}^{\mathrm{n}} v_{\mathrm{i}}\right) /(n+\lambda)$ where $\lambda=\sigma_{\mathrm{b}}^{2} / \sigma_{\mathrm{s}}^{2}$ is a measure of the (relative) quality of the auctioneer's information. 
Lemma 2 shows that with one more bidder the expected cost of the winner falls even when the uncertainty about the common value is increased by scaling the value signals by $\alpha_{0}=(n+1) / n$. The next result should therefore come as no surprise.

Proposition 10. Total expected surplus increases with the number of bidders and attains its maximum value, $E(V)-c_{L}$, in the limit as the number of bidders goes to infinity.

Proof. From Proposition 6 and Lemma 2: $\mathrm{E}_{\mathrm{n}+1}\left(c \mid s^{\prime}=Y_{1}^{\prime}\right)<\mathrm{E}_{\mathrm{n}+1}\left(c \mid s^{\prime}\left(\alpha_{0}\right)=Y_{1}^{\prime}\left(\alpha_{0}\right)\right) \leq \mathrm{E}_{\mathrm{n}}\left(c \mid s=Y_{1}\right)$. Since $W=\mathrm{E}(V)-\mathrm{E}\left(c \mid s=Y_{1}\right)$, the first part of the proposition follows. When $n \rightarrow \infty$, surplus reduces to $-c_{\mathrm{i}}$, so $\lim _{\mathrm{n} \rightarrow \infty} \mathrm{E}_{\mathrm{n}}\left(c_{1} \mid v_{1} / n-c_{1}=\max _{\mathrm{i}=1, \ldots, \mathrm{n}}\left(v_{\mathrm{i}} / n-c_{\mathrm{i}}\right)\right)=\lim _{\mathrm{n} \rightarrow \infty} \mathrm{E}_{\mathrm{n}}\left(c_{1} \mid c_{1}=\min _{\mathrm{i}=1, \ldots, \mathrm{n}} c_{\mathrm{i}}\right)=c_{\mathrm{L}}$. Hence, the limit value of the total expected surplus is $W=\mathrm{E}(V)-c_{\mathrm{L}}$. Q.E.D.

The effect of one more bidder on the winner's profit and the auctioneer's expected revenue can be dealt with similarly. We scale the values by $\alpha_{0}=(n+1) / n$ to isolate the effect of one more draw and then we take into account the effect of the surplus redefinition. The winner's profit can be written in terms of the (inverse of the) hazard rate $h(x)=\left(1-F_{\mathrm{s}}(x)\right) / f_{\mathrm{s}}(x)$ (see, for instance, McAfee and McMillan, 1987):

$$
\pi_{\text {winner }}=\int_{s_{L}}^{s_{H}} h(x)^{-1} d F_{s}^{n}(x) .
$$

First, consider the transition from $n$ to $n+1$ bidders while scaling the value signals by $\alpha_{0}$ so that the definition of a bidder's surplus remains the same. The winner's expected profits are then given by (7) with $F^{\mathrm{n}}$ replaced by $F^{\mathrm{n}+1}$. Since logconcavity ensures that the inverse hazard rate, $1 / h(x)$, is everywhere non-decreasing (see Lemma A2 in the Appendix) and $F^{\mathrm{n}+1}$ first-order stochastically dominates $F^{\mathrm{n}}$, the resulting profit is no higher than (7). Combining this result with Proposition 7, shows that the winner's profit does not rise with the number of bidders. With higher total surplus and winner's profits that are at most the same we conclude:

Proposition 11. Increased competition raises the auctioneer's expected revenue and does not raise the winner's expected profit. 
Interestingly, the effect of one more bidder on efficiency and revenues is greater than the effect of information disclosure by the auctioneer, at least when the auctioneer's signal is not more precise than a bidder's signal. Both lead to the same redefinition of the surplus $(s=v / n-c$ is replaced by $\left.s^{\prime}=v /(n+1)-c\right)$ which has positive effects on revenues and efficiency since it reduces the uncertainty of the common value. However, in the case of one more bidder there is also one more value and cost draw, which further lowers the winner's expected cost. When faced with the choice to gather more information or to attract more bidders, a seller may want to choose for the latter.

\section{An Example}

In this section we illustrate the effects of uncertainty, information disclosure, and competition on efficiency with a specific example. In previous sections the private signal represented a bidder's cost but alternative interpretations are possible. For instance, the private value could represent a bidder's idiosyncratic taste for a painting while estimates of the resale price add a common value part. Suppose each bidder receives signals $\left(t_{\mathrm{i}}, v_{\mathrm{i}}\right)$ where $t_{\mathrm{i}} \geq 0$ is the private value signal and $v_{\mathrm{i}} \geq 0$ is the common value signal. It is straightforward to adapt the optimal bidding functions of section 4 for this case. Here we are mainly interested in the level of achieved efficiency and we shall only need the fact that optimal bids are increasing functions of $v / n+t$. Since the common value part is the same for all bidders, efficiency only depends on the private value differences. For illustrative purposes we consider the following efficiency measure that takes values between 0 and 100 percent:

$$
\Omega=\frac{t_{\text {winner }}-t_{\min }}{t_{\max }-t_{\min }} \times 100 \%
$$

where $t_{\max }, t_{\min }$, and $t_{\text {winner }}$ are the maximum taste draw, the minimum taste draw, and the winner's taste respectively. ${ }^{15}$ The expected value of $\Omega$ is in general hard to compute since it is a ratio

15 Most efficiency results of this paper also hold for this measure: less uncertainty about the common value raises $\Omega$, the disclosure of the auctioneer's information raises $\Omega$, and $\Omega$ attains its maximum value of 100 percent when the number of bidders goes to infinity. 
of stochastic variables, but $\Omega$ can be simulated easily. Consider the example when private values are uniformly distributed on [7,8] and the common values are uniform on $[5,10]$. Figure 2 shows the attained efficiency level as a function of the number of bidders (bottom line), both with the public announcement of the auctioneer's signal (middle line), and one extra bidder (top line). ${ }^{16}$ The efficiency loss is substantial with only a few bidders and disappears as more bidders enter the auction. As argued in section 7, the effect of increased competition is greater than the public disclosure of the auctioneer's information.

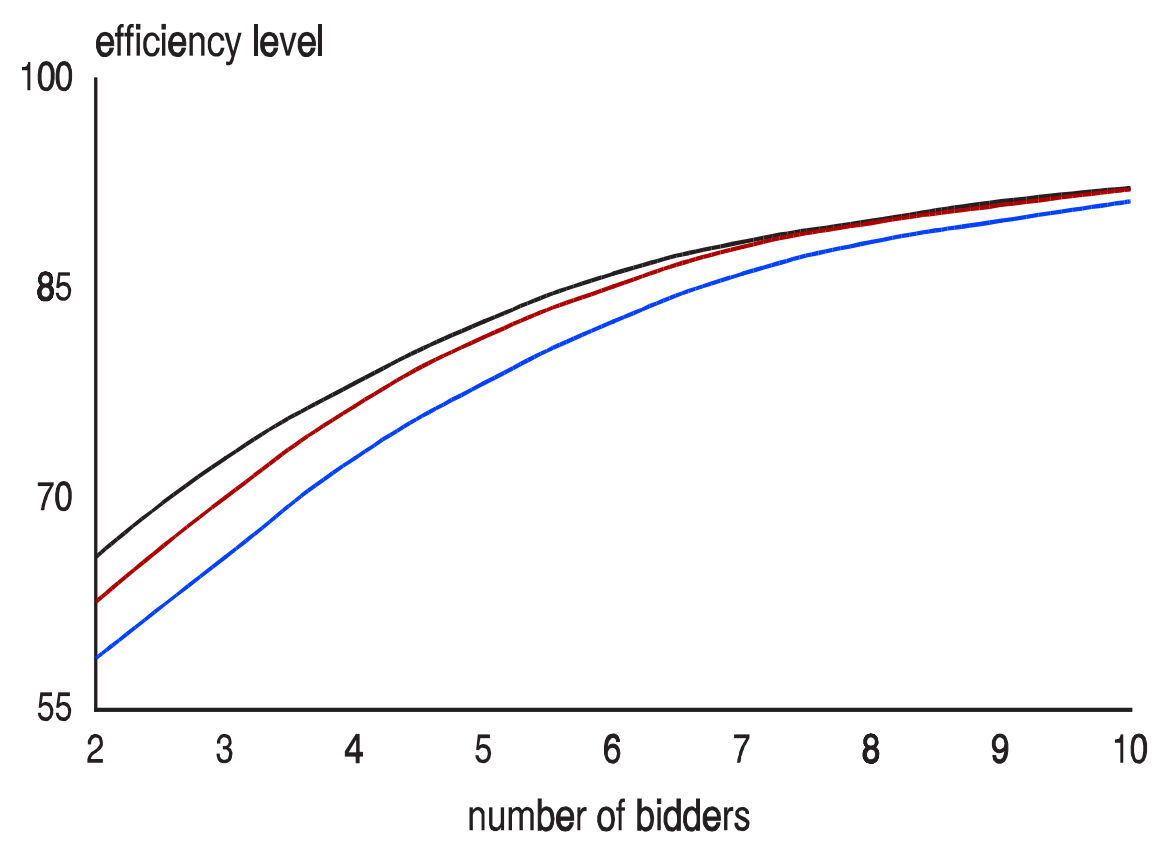

Figure 2. Efficiency as a function of the number of bidders.

The effect of uncertainty about the common value is illustrated in Figure 3, where the expected efficiency level is plotted as a function of the number of bidders. The private value signals are again uniformly distributed on $[7,8]$ and the common value signals are uniformly

16 Since the private value signals are symmetrically distributed the lowest possible level of efficiency is 50 percent. When the auction is no more efficient than a random allocation, symmetry implies that the winner's cost will, on average, lie halfway between the minimum and maximum taste draw. 


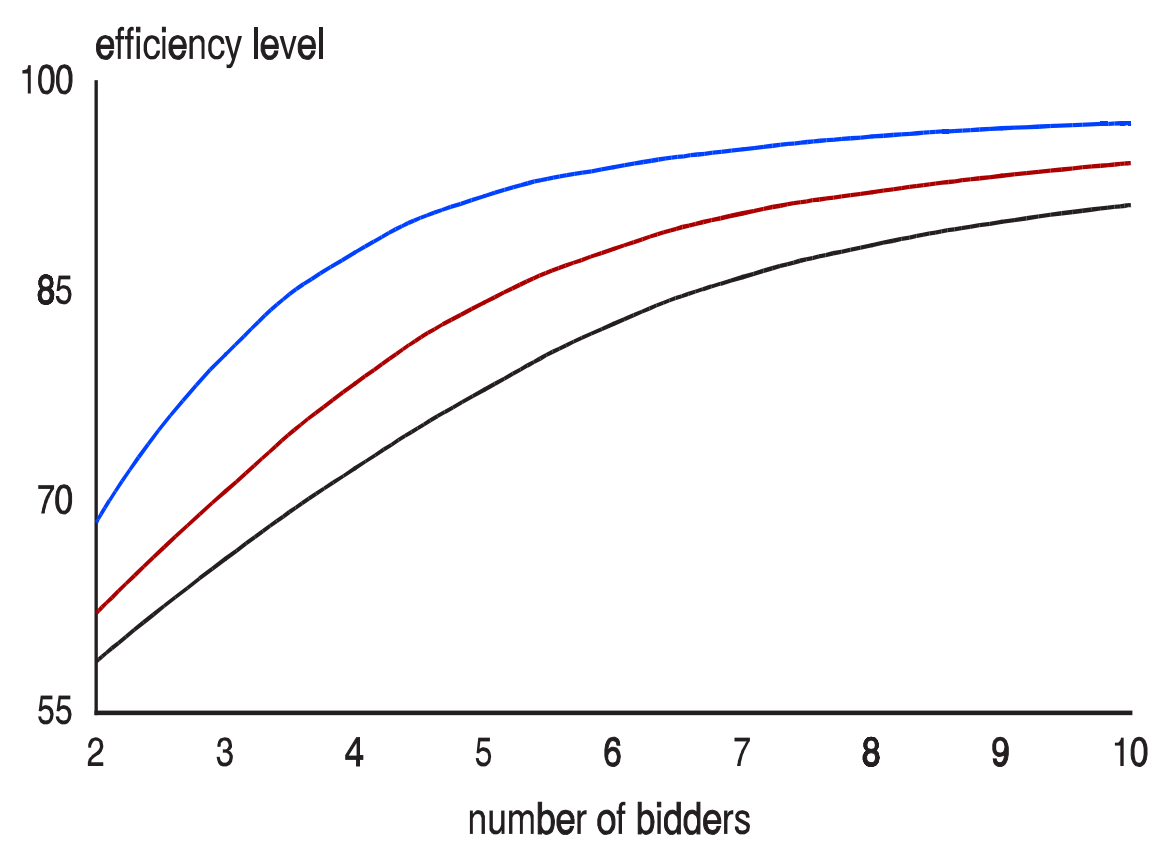

Figure 3. Efficiency for various levels of uncertainty about the common value.

distributed on [7, 8] (top line), [6, 9] (middle line), and [5, 10] (bottom line). Note that efficiency decreases when the uncertainty increases, even though the mean of the common value distribution remains unchanged.

\section{Conclusion}

Currently many governments use auctions to allocate licenses for industries with technically limited entry. The results reported in this paper temper an overly enthusiastic attitude towards auctions: when the object for sale has both private and common value elements, inefficiencies should be expected (see also Dasgupta and Maskin, 1999; Jehiel and Moldovanu, 1999). In all standard auction formats, bidders with a superior private value but a pessimistic signal about the common value can lose against bidders with an inferior private value but an optimistic common value signal. The magnitude of the efficiency losses depends on the degree of uncertainty about the common value: more uncertainty implies a higher level of expected 
inefficiency. It is thus easy to construct (theoretical) examples that generate large inefficiencies.

We do not suggest, however, to abandon the use of auctions when allocating scarce rights of entry. Only in the extreme case when the common value information completely overrides the private value information, do auctions approach the more or less random allocation of traditional methods like administrative procedures, lotteries, and "first come first serve." In this sense, our analysis still supports McMillan's (1995) argument that auctioning licenses to operate in a market should be favored over such traditional methods. However, the auctioneer can and should actively try to reduce expected inefficiencies. Our analysis provides two tools that raise efficiency. First, the auctioneer can obtain an own estimate of the common value and the public disclosure of this information increases expected efficiency. The higher the quality of the auctioneer's report, the higher the expected efficiency generated by the auction. Second, the auction should be designed such that all potentially interested bidders indeed participate, since more competition results in a more efficient allocation. These results are illustrated in Figures 2 and 3: efficiency losses can be substantial with only two or three bidders, but are negligible with seven bidders or more.

Our results suggest a number of directions for future research. One (technical) extension of our approach is to assume that value signals and/or cost signals are affiliated (Milgrom and Weber, 1982). Affiliation can be seen as a (strong) form of positive correlation. The logic spelled out in the first paragraph of section 3 also applies to the affiliated case: a bidder's expected payment and the probability of winning do not depend on a bidder's cost or value signal but only on her bid and the others' bidding strategies. For the average formulation of the common value, the way in which a bidder's value and cost enter the expected payoff is in the form of the surplus $s=v / n-c$. Hence, also in the affiliated case, optimal bids are functions of a bidder's surplus; the bidder with the highest surplus wins, and since this is not necessarily the bidder with the lowest cost, inefficiencies can occur. In addition, Propositions 5 and 6 that concern the degree of expected inefficiency do not hinge upon the independence assumption and thus carry over to the affiliated case. This means that the effect of information disclosure by the auctioneer and the effect of increased competition generalize. The revenue (equivalence) results, however, are specific to the independence assumption.

In most of the auction literature, including this paper, the information available to 
individual bidders is exogenously determined. Persico (1999) considers a model with costly information acquisition and shows that the auction institution itself may affect the level of information accumulation. Persico's work pertains only to the univariate (affiliated) signal case, but the implications of his work for our model are intriguing. Indeed, if it is the case, as in Persico (1999), that first-price auctions result in more information accumulation than second-price auctions, they may well achieve a higher level of efficiency. This conjecture may be hard to prove since auctions in which bidders possess different amounts of information are notoriously hard to analyze, but initial results from simple two-bidder auctions are encouraging.

In situations where the same set of bidders interacts repeatedly, it is possible that social ties develop between bidders which might lead them to work together. Our static model does not address the possibility of collusion among the bidders. ${ }^{17}$ It would be interesting, however, to determine the effects of collusion in our model: suppose bidders can find a mechanism to truthfully communicate their information (private and common value) to the other members of their bidding ring. Paradoxically, this may improve efficiency for two reasons. First, each bidding ring selects among its members the bidder with the best private value, thus lowering the chance that a bidder with an inferior value wins the auction. Second, when members of a bidding ring pool their information about the common value, the uncertainty about the common value diminishes, which further mitigates the possibility of inefficiencies. On the other hand, collusion also implies that there are fewer bidders, which has a negative effect on efficiency.

Our results have implications for structural econometric models of auctions (e.g. Laffont, Ossard, and Vuong, 1995). Such models start with the equilibrium bidding functions for either the private or common value case and use data on winning bids to determine the distribution of bidders' values. This information can be used by the seller to determine the optimal reservation price. Our approach may prove useful in finding the right specification, i.e. correct bidding functions, for auctions with multi-dimensional signals.

17 See, for instance, Graham and Marshall (1987) for an analysis of collusion in second-price and English auctions with private values. McAfee and McMillan (1992) consider collusion in first-price auctions and McAfee et al. (1989) discuss collusion in a common value setting. Robinson (1985) investigates the stability of bidding rings for various auction forms. Krishna and Morgan (1997) study the effects of joint bidding in a common value auction using the average formulation for the common value employed in this paper. 
Finally, the techniques developed in this paper can be applied in the analysis of other situations of economic interest. For instance, Feddersen and Pesendorfer (1997) argue that both private and common value aspects play a role in elections: voters' preferences over candidates' positions constitute a private value component, while the "quality" of the candidate can be interpreted as a common value element. Likewise, when money is being spent on a public good such as national defense, the private tastes of those living close to a base may differ from the common preference for protection and stability. In Cournot market games, firms' costs are private while the level of demand forms a common value element. In this case, a firm that is overly optimistic about demand may produce more than a more efficient rival. In any of these examples, the approach of this paper facilitates the analysis of equilibrium behavior in the presence of private and common values. 


\section{Appendix: Proofs}

Below we shall need the following properties implied by logconcavity.

Lemma A1. If $f(x, y)$ is logconcave then so are its marginals $f(x)$ and $f(y)$.

Proof. See An (1998).

Corollary A1. The density $f_{s}(s)$ is logconcave in $s$.

Proof. The joint density of $v$ and $s$ is given by $f(v, s)=f_{\mathrm{v}}(v) f_{\mathrm{c}}(v / n-s)$. It is straightforward to verify that under Assumption 2 the Hessian of $\log (f(v, s))$ is negative semi-definite, i.e. $f(v, s)$ is logconcave. Lemma A1 thus implies that $f_{\mathrm{s}}(s)$ is logconcave. Q.E.D.

Lemma A2. The hazard rate, $h(x)=f(x) /(1-F(x))$, of a logconcave density, $f(x)$, is everywhere non-decreasing.

Proof. Let $f(x)$ be logconcave then

$$
f^{\prime}(x)(1-F(x))=\int_{x}^{x_{H}} f^{\prime}(x) f(t) d t \geq \int_{x}^{x_{H}} f^{\prime}(t) f(x) d t \geq-f(x)^{2},
$$

where the first inequality follows since logconcavity of $f$ implies that $f^{\prime}(x) / f(x)$ is non-increasing in $x$, so $f^{\prime}(x) / f(x) \geq f^{\prime}(t) / f(t)$ for all $t \geq x$. It is straightforward to rewrite the above equation as: $(f(x) /(1-F(x)))^{\prime} \geq 0$. Q.E.D.

Lemma A3. Let $X$ and $Y$ be random variables. The conditional expectation $E(Y \mid X \leq x)$ satisfies

$$
\frac{\partial}{\partial x} E(Y \mid X \leq x)=(E(Y \mid X=x)-E(Y \mid X \leq x)) \frac{f_{X}(x)}{F_{X}(x)} .
$$

Proof. Write the conditional expectation $\mathrm{E}(Y \mid X \leq x)$ as

$$
E(Y \mid X \leq x)=\int_{x_{L}}^{x} E(Y \mid X=t) \frac{f_{X}(t)}{F_{X}(x)} d t .
$$

Differentiating the right side with respect to $x$ yields the desired result. Q.E.D. 
Proof of Lemma 1. Since $f(v \mid s)=f_{\mathrm{v}}(v) f_{\mathrm{c}}(v / n-s) / f_{\mathrm{s}}(s)$, logconcavity of $f_{\mathrm{c}}(\cdot)$ is equivalent to

$$
\partial_{v} \partial_{s} \log (f(v \mid s)) \geq 0 \text {. }
$$

This means that $\partial_{\mathrm{s}} \log (f(v \mid s))=\partial_{\mathrm{s}} f(v \mid s) / f(v \mid s)$ is increasing in $v$, or, $\partial_{\mathrm{s}} f\left(v_{1} \mid s\right) / f\left(v_{1} \mid s\right) \geq \partial_{\mathrm{s}} f\left(v_{2} \mid s\right) / f\left(v_{2} \mid s\right)$ for all $v_{1} \geq v_{2}$. This inequality can be rewritten as $\partial_{\mathrm{s}}\left(f\left(v_{1} \mid s\right) / f\left(v_{2} \mid s\right)\right) \geq 0$. Hence, for all $s_{1} \geq s_{2}$ we have $f\left(v_{1} \mid s_{1}\right) f f\left(v_{2} \mid s_{1}\right) \geq f\left(v_{1} \mid s_{2}\right) / f\left(v_{2} \mid s_{2}\right){ }^{18}$ Since this is true for all $v_{1} \geq v_{2}$, it remains true if we integrate $v_{1}$ from $v$ to $v_{\mathrm{H}}$ and integrate $v_{2}$ from $v_{\mathrm{L}}$ to $v$, which yields $\left(1-F\left(v \mid s_{1}\right)\right) / F\left(v \mid s_{1}\right) \geq$ $\left(1-F\left(v \mid s_{2}\right)\right) / F\left(v \mid s_{2}\right)$, or, $F\left(v \mid s_{1}\right) \leq F\left(v \mid s_{2}\right)$. In other words, $F\left(v \mid s_{1}\right)$ first-order stochastically dominates $F\left(v \mid s_{2}\right)$, which implies $E\left(v \mid s_{1}\right) \geq E\left(v \mid s_{2}\right)$ for all $s_{1} \geq s_{2}$. So $E(v \mid s=x)$ is non-decreasing in $x$. Lemma A3 applied to $X=s, Y=v$ yields: $\partial_{\mathrm{x}} E(v \mid s \leq x)=(E(v \mid s=x)-E(v \mid s \leq x)) f_{\mathrm{s}}(x) / F_{\mathrm{s}}(x)$, which is non-negative since $E(v \mid s=x)$ is non-decreasing in $x$. The proofs for the conditional expectations of the cost are similar. Q.E.D.

Below we use the following notation. The conditional density of $y_{1}$ given $y_{1} \leq s$ is: $f_{\mathrm{y} 1}\left(x \mid y_{1} \leq s\right)$ $=f_{\mathrm{y} 1}(x) / F_{\mathrm{y} 1}(s)=(n-1) f_{\mathrm{s}}(x) F_{\mathrm{s}}(x)^{\mathrm{n}-2} / F_{\mathrm{s}}(s)^{\mathrm{n}-1}$ for $x \leq s$, and the corresponding distribution function is $F_{\mathrm{y} 1}\left(x \mid y_{1} \leq s\right)=F_{\mathrm{s}}(x)^{\mathrm{n}-1} / F_{\mathrm{s}}(s)^{\mathrm{n}-1}$.

Proof of Proposition 1. An equivalent way to write (2) is: $B(x)=(n-1) / n \mathrm{E}(v \mid s \leq x)+\mathrm{E}\left(y_{1} \mid y_{1} \leq x\right)$ and its derivative is easily derived from Lemma A3: $B^{\prime}(x)=(n-1) / n(\mathrm{E}(v \mid s=x)-\mathrm{E}(v \mid s \leq x)) f_{\mathrm{s}}(x) / F_{\mathrm{s}}(x)$ $+\left(x-\mathrm{E}\left(y_{1} \mid y_{1} \leq x\right)\right) f_{\mathrm{y} 1}(x) / F_{\mathrm{y} 1}(x)$. The last term is positive (the event $y_{1}=x$ occurs with probability zero) and the first term is non-negative by Lemma 1 . Hence, $B(\cdot)$ is increasing. Suppose that bidders $2, \ldots, n$ bid according to (2). Bidder 1's expected profit is:

$$
\pi_{1}^{e}(b)=\left(s_{1}+\frac{n-1}{n} E\left(v \mid s \leq B^{-1}(b)\right)-b\right) F_{s}^{n-1}\left(B^{-1}(b)\right) .
$$

From Lemma A3, the derivative of the expected profit with respect to $b$ evaluated at $b=B(x)$ is:

$$
\pi_{1}^{e}{ }_{1}^{\prime}(B(x))=\frac{f_{y_{1}}(x)}{B^{\prime}(x)}\left(s_{1}+\frac{1}{n} E(v \mid s=x)+\frac{n-2}{n} E(v \mid s \leq x)-B(x)-B^{\prime}(x) \frac{F_{y_{1}}(x)}{f_{y_{1}}(x)}\right) .
$$

Using the expression for $B^{\prime}$ derived above it is straightforward to verify that the term in the brackets equals $s_{1}-x$. Together with monotonicity of $B(\cdot)$ this shows that $B\left(s_{1}\right)$ is bidder 1's unique optimal bid. Q.E.D.

18 In other words, $f(v \mid s)$ satisfies the monotone likelihood property, see Milgrom (1981). 
Proof of Proposition 2. Note that (3) is equivalent to: $B(x)=x+1 / n \mathrm{E}(v \mid s=x)+(n-2) / n \mathrm{E}(v \mid s \leq x)$. The last two terms are non-decreasing in $x$ (Lemma 1), so $B(\cdot)$ is increasing. Assume that bidders $2, \ldots, n$ bid according to (3). Bidder 1's expected payoff is:

$$
\pi_{1}^{e}(b)=\left(s_{1}+\frac{n-1}{n} E\left(v \mid s \leq B^{-1}(b)\right)-\int_{s_{L}}^{B^{-1}(b)} B(x) f_{y_{1}}\left(x \mid s \leq B^{-1}(b)\right) d x\right) F_{s}^{n-1}\left(B^{-1}(b)\right) .
$$

The second term in the brackets on the right side represents the sum of the values of bidders 2 to $n$ given that their surpluses are less than $B^{-1}(b)$. An equivalent way of writing this term is by choosing one of them to have the highest surplus, $y_{1} \leq B^{-1}(b)$, while the $n-2$ others have surpluses less than or equal to $y_{1}$. The expected profit then becomes

$$
\pi_{1}^{e}(b)=\int_{s_{L}}^{B^{-1}(b)}\left(s_{1}+\frac{1}{n} E(v \mid s=x)+\frac{n-2}{n} E(v \mid s \leq x)-B(x)\right) f_{y_{1}}(x) d x=\int_{s_{L}}^{B^{-1}(b)}\left(s_{1}-x\right) d F_{y_{1}}(x) .
$$

Together with monotonicity of $B^{-1}(\cdot)$ this proves that the unique optimal bid is $B\left(s_{1}\right)$. Q.E.D.

Proof of Proposition 3. Note that each $B_{\mathrm{k}}$ is strictly increasing in $x$. Suppose bidders $2, \ldots, n$ bid according to (4). When bidder 1 wins the auction her expected profit is: $s_{1}+1 / n \sum_{\mathrm{j}=1}^{\mathrm{n}-1} \mathrm{E}\left(v \mid s=s_{\mathrm{j}+1}\right)$ - $B_{\mathrm{n}-2}\left(s_{2}\right)$, where the $s_{\mathrm{j}}$ are the realizations of the others' surpluses arranged in increasing order, i.e. $s_{2} \geq \ldots \geq s_{\mathrm{n}}$. Using the definition of $B_{\mathrm{n}-2}$ the expected payoff can be written as: $s_{1}+1 / n$ $\mathrm{E}\left(v \mid s=s_{2}\right)-2 / n \mathrm{E}\left(v \mid s=s_{2}\right)+\mathrm{E}\left(c \mid s=s_{2}\right)=s_{1}-s_{2}$. So bidder 1's expected profit is positive only when she has the highest surplus, and using $B(\cdot)$ she wins iff $s_{1}=Y_{1}$. Hence, $B(\cdot)$ is the optimal bidding strategy for player 1. Q.E.D.

Proof of Proposition 4. Expected total surplus equals the winner's valuation of the commodity:

$$
W=\int_{s_{L}}^{s_{H}}\left(x+\frac{n-1}{n} E(v \mid s \leq x)\right) f_{Y_{1}}(x) d x,
$$

so $W=\mathrm{E}\left(s \mid s=Y_{1}\right)+(n-1) / n \mathrm{E}\left(v \mid s \leq Y_{1}\right)=1 / n \mathrm{E}\left(v \mid s=Y_{1}\right)+(n-1) / n \mathrm{E}\left(v \mid s \leq Y_{1}\right)-\mathrm{E}\left(c \mid s=Y_{1}\right)$. The first two terms represent the expected value of the commodity given that one bidder has the highest surplus and the others have lower surpluses: this is just $\mathrm{E}(V)$. Hence $W=\mathrm{E}(V)-\mathrm{E}\left(c \mid s=Y_{1}\right)$.

The Envelope Theorem implies that the derivative of the equilibrium profit $\pi^{*}(s)=$ $\pi^{\mathrm{e}}(B(s))$ with respect to a bidder's surplus $s$ equals the equilibrium probability of winning. When surpluses are i.i.d. across bidders the equilibrium probability of winning is simply $F_{\mathrm{s}}(s)^{\mathrm{n}-1}$ and the equilibrium profit is therefore $\pi^{*}(s)=\int_{\mathrm{sL}}^{\mathrm{s}} F_{\mathrm{s}}(x)^{\mathrm{n}-1} \mathrm{~d} x$. This is the expected equilibrium profit of a 
bidder with surplus $s$ in any of the three auctions discussed above. The ex ante expected equilibrium payoffs accrue to the winning bidder, so

$$
\pi_{\text {winner }}=n \int_{s_{L}}^{s_{H}} \int_{s_{L}}^{s} F_{s}^{n-1}(x) d x d F_{s}(s)=n \int_{s_{L}}^{s_{H}}\left(1-F_{s}(x)\right) F_{s}^{n-1}(x) d x,
$$

where the last expression is obtained by changing the order of integration. Partially integrating this expression yields: $\pi_{\text {winner }}=\mathrm{E}\left(Y_{1}\right)-\mathrm{E}\left(Y_{2}\right)$. Finally, revenue is the difference between total surplus and the winner's profit: $R=W-\pi_{\text {winner }}=W-\mathrm{E}\left(Y_{1}\right)-\mathrm{E}\left(Y_{2}\right)$. Q.E.D.

Proof of Proposition 6. The distribution function, $F_{\mathrm{s}(\alpha)}(x)$, of $s(\alpha)=\alpha v / n-c$ is given by

$$
F_{s(\alpha)}(x)=\int_{v_{L}}^{v_{H}} f_{v}(v)\left(1-F_{c}(\alpha v / n-x)\right) d v
$$

from which it follows that $\mathrm{d} F_{\mathrm{s}(\alpha)}(x) / \mathrm{d} \alpha=-1 / n \mathrm{E}(v \mid s(\alpha)=x) f_{\mathrm{s}(\alpha)}(x) \leq 0$, i.e. the distribution $F_{\mathrm{s}(\alpha)}(\cdot)$ is stochastically increasing in $\alpha$. The difference between the first and second order statistic is:

$$
E\left(Y_{1}(\alpha)\right)-E\left(Y_{2}(\alpha)\right)=n \int_{s_{L}(\alpha)}^{s_{H}(\alpha)} F_{s(\alpha)}^{n-1}(x)\left(1-F_{s(\alpha)}(x)\right) d x
$$

Differentiating this expression with respect to $\alpha$ yields

$$
\frac{d\left(E\left(Y_{1}(\alpha)\right)-E\left(Y_{2}(\alpha)\right)\right)}{d \alpha}=\frac{1}{n}\left(E\left(v \mid s(\alpha)=Y_{1}(\alpha)\right)-E\left(v \mid s(\alpha)=Y_{2}(\alpha)\right)\right)
$$

Lemma 1 together with $Y_{1}(\alpha) \geq Y_{2}(\alpha)$ ensures that the right side is non-negative. Q.E.D.

\section{Proof of Lemma 2.}

$$
E_{n}\left(c \mid s=Y_{1}\right)=\int_{s_{L}}^{s_{H}} E(c \mid s=x) d F_{s}^{n}(x)
$$

and

$$
E_{n+1}\left(c \mid s^{\prime}\left(\alpha_{0}\right)=Y_{1}^{\prime}\left(\alpha_{0}\right)\right)=\int_{s_{L}}^{s_{H}} E(c \mid s=x) d F_{s}^{n+1}(x) .
$$

The result follows since $F^{\mathrm{n}+1}(\cdot)$ first-order dominates $F^{\mathrm{n}}(\cdot)$ and $\mathrm{E}(c \mid s=x)$ is non-increasing in $x$. 


\section{References}

Albers, Wulf and Ronald M. Harstad (1991) "Common-Value Auctions with Independent Information: A Framing Effect Observed in a Market Game," in R. Selten, ed., Game Equilibrium Models: Volume II, Berlin: Springer-Verlag.

An, Mark Y. (1998) "Logconcavity versus Logconvexity: A Complete Characterization," Journal of Economic Theory, 80, 350-369.

Ashenfelter, Orley (1989) "How Auctions Work for Wine and Art," Journal of Economic Perspectives, 3(3), 23-26.

Bikhchandani, Sushil and John G. Riley (1991) "Equilibria in Open Common Value Auctions," Journal of Economic Theory, 53, 101-130.

Bulow, Jeremy I. and Paul D. Klemperer (1996) "Auctions versus Negotiations," American Economic Review, 86(1), 180-194.

Bulow, Jeremy I. and Paul D. Klemperer (1999) "Prices and the Winner's Curse," working paper.

Bulow, Jeremy I., Huang, M. and Paul D. Klemperer (1999) "Toeholds and Takeovers," Journal of Political Economy, 107(3), 427-454.

Caplin, Andrew and Barry Nalebuff (1991) "Aggregation and Imperfect Competition: On the Existence of Equilibrium," Econometrica, 59(1), 25-59.

Dasgupta, P. and Eric S. Maskin (1999) "Efficient Auctions," Quarterly Journal of Economics, forthcoming.

Feddersen, Timothy and Wofgang Pesendorfer (1997) "Voting Behavior and Information Aggregation in Elections with Private Information," Econometrica, 65(5), 1029-58.

Graham, Daniel A. and Robert C. Marshall (1987) "Collusive Bidder Behavior at Single-Object Second-Price and English Auctions," Journal of Political Economy, 95, 1217-1239.

Jackson, Matthew O. (1999) "The Non-Existence of Equilibrium in Auctions with TwoDimensional Types," working paper, California Institute of Technology.

Jehiel, Philippe and Benny Moldovanu (1999) "Efficient Design with Interdependent Valuations," working paper, Mannheim University.

Holt, Charles A. (1980) "Competitive Bidding for Contracts Under Alternative Auction Procedures," Journal of Political Economy, 88, 433-445.

Klemperer, Paul D. (1998) "Auctions With Almost Common Values," European Economic Review, 42, 757-769.

Klemperer, Paul D. (1999) "Auction Theory: A Guide to the Literature," Journal of Economic Surveys, 13(3), 227-286. 
Krishna, Vijay and John Morgan (1997) "(Anti-) Competitive Effects of Joint Bidding and Bidder Restrictions," working paper, Penn State University and Princeton University.

Laffont, Jean-Jacques, Herve Ossard, and Quang Vuong (1995) "Econometrics of First-Price Auctions," Econometrica, 63(4), 953-980.

Laffont, Jean-Jacques (1997) "Game Theory and Empirical Economics: The Case of Auction Data," European Economic Review, 41, 1-35.

Maskin, Eric S. (1992) "Auctions and Privatization," in Privatization (ed. by H. Siebert), Institut fur Weltwirtschaften der Universitat Kiel, 115-136.

McAfee, Preston R. and John McMillan (1987) "Auctions and Bidding," Journal of Economic Literature, $X X V(2), 699-738$.

McAfee, Preston R. and John McMillan (1992) "Bidding Rings," American Economic Review, 82(3), 579-599.

McMillan, John (1995) "Why Auction the Spectrum?" Telecommunications Policy, 19(3), 191199.

Milgrom, Paul R. (1981) "Good News and Bad News: Representation Theorems and Applications," The Bell Journal of Economics, 12(2), Autumn, 380-391.

Milgrom, Paul R. and Robert J. Weber (1982) "A Theory of Auctions and Competitive Bidding," Econometrica, 50(5), 1089-1121.

Paarsch, Harry (1992) "Deciding Between the Common and Private Value Paradigms in Empirical Models of Auctions," Journal of Econometrics, 51, 191-215.

Persico, Nicola (1999) "Information Acquisition in Auctions," Econometrica, forthcoming.

Pesendorfer, Wolfgang and Jeroen M. Swinkels (1999) "Efficiency and Information Aggregation in Auctions," American Economic Review, forthcoming.

Robinson, Marc S. (1995) "Collusion and the Choice of Auction," RAND Journal of Economics, 16(1), Spring, 141-145.

Rothkopf, Michael H. (1969) "A Model of Rational Competitive Bidding," Management Science, 15, 362-373.

Vickrey, William (1961) "Counterspeculation, Auctions, and Sealed Tenders," Journal of Finance, 16, 8-37.

Wilson, Robert (1969) "Competitive Bidding with Disparate Information," Management Science, $15,446-448$.

Wilson, Robert (1977) "A Bidding Model of Perfect Competition," Review of Economic Studies, 44, 511-518. 